\title{
Anti-atherosclerotic Drugs from Natural Products
}

\author{
Alexander N Orekhov ${ }^{1,2 *}$ \\ ${ }^{1}$ Institute for Atherosclerosis Research, Skolkovo Innovative Center, Moscow, Russia \\ ${ }^{2}$ Institute of General Pathology and Pathophysiology, Russian Academy of Medical Sciences, Russia
}

\begin{abstract}
Atherosclerosis is the cause of more than $50 \%$ mortality in industrial countries. Atherosclerosis develops over many years, so the anti-atherosclerotic therapy should be long-term or even lifelong. Tachyphylaxis, long-term toxicity and cost amongst other issues may present problems for the use of conventional medications in the long-term. Drugs based on natural products can be a good alternative.

We have developed a series of natural compounds that are specifically designed to act at the vessel wall and modulate the atherosclerotic lesion. Clinical efficacy was determined in atherosclerosis regression studies with ultrasound examination of carotid arteries. The AMAR study (Atherosclerosis Monitoring and Atherogenicity Reduction) was designed to estimate the effect of two-year treatment with time-released garlic-based drug Allicor on the progression of carotid atherosclerosis in asymptomatic men in double-blinded placebo-controlled randomized clinical trial. The primary outcome was the rate of atherosclerosis progression, measured by high-resolution B-mode ultrasonography as the increase in carotid intima-media thickness (IMT) of the far wall of common carotid arteries. The mean rate of IMT changes in Allicor-treated group was significantly different from the placebo group in which there was moderate progression. The results of AMAR study demonstrate that long-term treatment with Allicor has a direct anti-atherosclerotic effect on carotid atherosclerosis. These results encouraged clinical trials of two other drugs based on natural products, including: Inflaminat (calendula, elder and violet), possessing anti-cytokine activity and the phytoestrogen-rich drug Karinat (garlic powder, extract of grape seeds, green tea leafs, hop cones, $\beta$-carotene, a-tocopherol and ascorbic acid), designed for postmenopausal women. As in the AMAR trial Inflaminat caused regression of carotid atherosclerosis while Karinat prevented its development.
\end{abstract}

It should be noted that the anti-atherosclerotic effects of drugs based on natural products are not inferior to the effects of such drugs as statins and calcium antagonists. Thus, natural products can be considered as promising drugs for anti-atherosclerotic therapy.

Keywords: Allicor; Anti-Atherosclerotic therapy; Atherosclerosis; Cell culture; Drugs; Imaging; Intracellular cholesterol retention; Natural products

Abbreviations: AMAR: Atherosclerosis Monitoring and Atherogenicity Reduction; CIMT: Carotid Intima-media Thickness; HDL: High-density Lipoprotein; LDL: Low Density Lipoprotien

\section{Introduction}

Development of anti-atherosclerotic drugs is based on our current knowledge and hypotheses on the mechanisms of atherogenesis. The only hypothesis that has received confirmation in the clinic is the cholesterol hypothesis. This hypothesis was proposed more than 100 years ago by Nikolai Anitschkow. The Anitschkow's hypothesis linked atherosclerosis with high levels of total cholesterol in the blood. The modern paradigm only explains some aspects of this hypothesis, in particular as atherosclerosis is not associated with the total level of cholesterol but with atherogenic low-density lipoprotein (LDL) cholesterol and anti-atherogenic high-density lipoprotein (HDL) cholesterol [1-3].

Retention of intracellular lipids or lipidosis that is the accumulation of cholesterol and other lipids in the arterial cells is the most prominent manifestation of atherosclerosis at the arterial cell level. Williams and Tabas [4,5] proposed so-called the Response-to-Retention model of atherogenesis. Although atherosclerosis is a complex and multifactorial process, the key initiating process in atherogenesis is the sub endothelial cholesterol retention that is both necessary and sufficient to provoke lesion initiation. Retention of cholesterol transported by low density lipoprotien (LDL) in sub endothelial space of arterial wall is an absolute requirement for lesion development. According to Tabas et al. [6] the molecular basis of lipoprotein retention is associated with interaction of lipoprotein and extracellular matrix molecules. Local responses to these retained lipoproteins include inflammatory response with subsequent lesion development [7]. Specific focus is placed on the potential of these innate immune targets for therapeutic interventions to retard the progression of atherosclerosis or to induce its regression [8]. The response-to-retention model considers only the retention of cholesterol on extracellular matrix, while completely ignoring the retention of intracellular cholesterol.

Intracellular cholesterol retention is accompanied by increased proliferative activity of vascular cells and increased synthesis of extracellular matrix $[9,10]$. Along with the retention of intracellular cholesterol, both proliferation and fibrosis are characteristic features of atherosclerosis at the arterial cell level, too. Thus, intracellular cholesterol retention may be initial event of all major manifestations of atherosclerosis on cellular level. Intracellular cholesterol retention may be regarded as a novel target for anti-atherosclerotic therapy. This allows us to consider cellular retention of cholesterol as a novel target for anti-atherosclerotic therapy. In this case the target is not the level of blood cholesterol but the level of cholesterol in vascular cells.

This review summarizes the results of basic studies shedding

${ }^{*}$ Corresponding author: Alexander $\mathrm{N}$ Orekhov, Institute for Atherosclerosis Research, Skolkovo Innovative Center, Moscow, Russia, Tel: +7 90316908 66 Fax: +7 49541595 94; E-mail: a.h.opexob@gmail.com

Received July 27, 2013; Accepted September 11, 2013; Published September 17,2013

Citation: Orekhov AN (2013) Anti-atherosclerotic Drugs from Natural Products Nat Prod Chem Res 1: 121 doi:10.4172/ 2329-6836.1000121

Copyright: (c) 2013 Orekhov AN. This is an open-access article distributed under the terms of the Creative Commons Attribution License, which permits unrestricted use, distribution, and reproduction in any medium, provided the original author and source are credited. 
light on the mechanisms of intracellular retention of cholesterol. We describe our cellular models to search for anti-atherosclerotic agents and demonstrate the use of these models for the development of antiatherosclerotic drugs.

Atherosclerosis develops over many years, so the anti-atherosclerotic therapy should be long-term or even lifelong. Tachyphylaxis, long-term toxicity and cost amongst other issues may present problems for the use of conventional medications in the long-term. Drugs based on natural products can be a good alternative. We reported successful translation of innovative attempts and novel drugs from natural products into clinical practice.

\section{Basic Studies}

Intracellular retention of cholesterol is induced by LDL. It is well known that native lipoprotein usually does not increase the cholesterol content of the cell; however the incubation of cultured cells with chemically modified LDL results in a massive accumulation of cholesterol in the cells [11]. Thus, modified, but not native, LDL is the source of cholesterol retention in arterial cells. Cells populating atherosclerotic lesions are often overloaded with lipids, and their cytoplasms are almost completely filled with lipid inclusions [12]. These cells are referred to as foam cells because of foamy appearance of their cytoplasm.

In the blood of patients with coronary and extra coronary atherosclerosis we have discovered modified (desialylated) LDL [13-16]. This naturally occurring modified LDL induces cholesterol retention in cultured arterial cells [13-16]. Circulating modified LDL is multiple modified lipoprotein characterizing by lower sialic acid, triglyceride and cholesterol contents; smaller particle size; greater density and negative charge; higher aggregative activity; and some other specific features [17]. We have discovered an enzyme, trans-sialydase, which is responsible for the desialylation of LDL particles in the blood [18].

In addition to desialylated LDL, more electronegative LDL and small dense LDL have been found in human blood $[19,20]$. In cooperation with researchers who found more electronegative LDL and small dense LDL we carries out comparative studies and showed that the more electronegative LDL is desialylated LDL [21] as well as desialylated LDL isolated from patient blood [13-16] is more electronegative. Desialylated LDL particle is smaller and denser than that of native LDL [22] as well as small dense LDL isolated from patients has a low content of sialic acid, i.e., it is desialylated [23].

Modified (desialylated) LDL stimulates anti-LDL auto-antibodies production [24-28]. Anti-LDL auto-antibodies and modified LDL form LDL-containing circulating immune complexes [29]. We have demonstrated LDL-containing circulating immune complexes and anti-LDL auto-antibodies in the blood of atherosclerotic patients [2931]. We have also found a positive correlation between the levels of LDL-containing immune complexes and the severity of atherosclerosis [29-33]. LDL is able to form complexes with collagen, elastin, and proteoglycans isolated from human aortic intima [34-39]. These LDLcontaining complexes induce intracellular cholesterol retention as a result of increased uptake and decreased intracellular degradation of lipoproteins in complexes [38]. Naturally occurring multiple modified LDL has tendency to associate and forms self-associates, while native LDL does not associate [37]. We found a positive correlation between intracellular cholesterol retention caused by modified LDL and the degree of LDL self-association [37,38]. LDL-associates isolated by gel filtration were shown to induce dramatic intracellular cholesterol retention. Thus, the formation of large LDL containing complexes (self-associates, immune complexes, and complexes with connective tissue matrix) is a necessary and sufficient condition for intracellular cholesterol retention.

Our knowledge of mechanisms of intracellular cholesterol retention allowed us to consider the prevention of intracellular cholesterol retention as a target for anti-atherosclerotic therapy. As a model of intracellular cholesterol retention we use primary culture of sub endothelial aortic cells and modified LDL or blood serum containing modified LDL. We use this model for the development of anti-atherosclerotic drugs.

\section{Cellular Models}

Cells are isolated from the subendothelial part of the human aortic intima between the endothelial lining and the media [39]. Using collagenase and elastase, viable cells are isolated from the subendothelial layer of the intima [40-42]. Isolated cells can be classified as the mixture of smooth muscle cells, pericyte-like cells, and macrophages [39-43]. The culture on which our experiments are performed is represented by this mixed population [39].

Cells isolated from atherosclerotic lesions retain all major characteristics of atherosclerotic cells when cultured. They are capable of synthesizing collagen, proteoglycans and other components of the extracellular matrix [9]. Cell cultured from fatty lesions have an enhanced proliferative activity [41], higher than that of cells cultured from unaffected intima [44,45]. Considerable part of cells cultured from atherosclerotic lesions is foam cells, which contain numerous inclusions, likely lipid droplets, which fill the entirety of the cytoplasm [41]. Excess lipids in foam cells are mainly free cholesterol and cholesteryl esters [41]. It is important that the content and composition of lipids in cultured cells within the first 10-12 days in culture remain unchanged and correspond to the respective indices of freshly isolated cells $[41,45]$. Thus, our investigations are carried out directly on exactly those cells that require a therapeutic action in vivo.

To induce intracellular cholesterol retention we used blood sera obtained from coronary heart disease patients [46]. These sera contain modified LDL [11-14]. As a result serum is atherogenic, i.e., it is able to cause retention of intracellular cholesterol and stimulate other atherogenic manifestations in cultured cells [10,46-48]. Atherogenic serum was added to primary culture of subendothelial cells derived from an unaffected intima. Drug efficacy is judged by the ability to prevent the deposition of intracellular cholesterol in cultured cells. The prevention of intracellular cholesterol retention may be regarded as anti-atherosclerotic effect. In terms of arterial cells, any drug effect that does not directly prevent intracellular cholesterol retention is regarded as an indirect anti-atherosclerotic action. Only a drug that exhibits its preventive activity at the arterial level is a direct anti-atherosclerotic drug. Using this model, we have examined the effects of different drugs and chemicals.

Using our cellular model we have tested three classes of cardiovascular drugs, calcium antagonists, beta-blockers and nitrates. These drugs are widely used in clinics in the therapy of various disorders that resulted from atherosclerosis of different arteries. The effect of several calcium antagonists on intracellular cholesterol retention was tested. Verapamil and nifedipine completely inhibited the accumulation of intracellular cholesterol induced by the sera, while other calcium antagonists, such as diltiazem, nicardipine, isradipine, and darodipine, substantially reduced cholesterol accumulation [49]. The examined calcium antagonists demonstrated anti-atherogenic action in vivo by inhibiting the development of experimental atherosclerosis in animals 
[50,51]. Thus, our in vitro data obtained using the cellular model corresponds to the in vivo observations.

Nitrates and beta-blockers have been tested to examine their effect on atherosclerotic cellular indices. Nitrates only minimally affected cholesterol levels [52]. In contrast, all the examined beta-blockers, i.e., propranolol, alprenolol, metoprolol, pindolol, and timolol, increased intracellular cholesterol retention, i.e., all of these drugs exhibited proatherogenic activity in culture [49,52]. If beta-blockers have a similar effect in vivo, one may assume that these drugs are atherogenic and induce their atherogenic effects at the arterial cell level. Apparently, nitrates do not follow a similar trend.

Thus, three classes of cardiovascular drugs exert a different influence on intracellular cholesterol retention. Calcium antagonists exhibit anti-atherosclerotic actions. In contrast, beta-blockers are proatherogenic. Nitrates do not have an effect on intracellular cholesterol retention. Our data are consistent with the results of a clinical study reported by Loaldi et al. [53] who demonstrated that long-term oral administration of propranolol aggravates coronary atherosclerosis in patients with angina of effort compared with the calcium antagonists' nifedipiene and isorobide dinitrate. Nifedipine showed the best effect on coronary atherosclerosis by suppressing the development of existing atherosclerotic lesions and preventing the appearance of new lesions. Isosorbide dinitrate was less effective. These clinical observations confirming our in vitro results encourage us to develop an antiatherosclerotic therapy using our cellular model.

Naturally, the question arises whether the anti-atherosclerotic effects revealed in in vitro cellular model can be manifested in vivo. To answer this question, an ex vivo model was developed. In the ex vivo model, instead of agents, blood sera taken from patients after oral drug administration is added to cultured cells.

Two calcium antagonists, verapamil and nifedipin, and two betablockers, propranolol and pindolol, were examined using the ex vivo model $[52,54]$. Within 2-4 hours after nifedipine or verapamil oral administration, the patients' sera were less atherogenic; i.e., induced less intracellular cholesterol retention. In contrast, the sera of patients who received propranolol or pindolol were pro-atherogenic. Its proatherogenic properties manifested themselves at the arterial cell level via the rise of intracellular cholesterol accumulation. This finding allows us to assume that not only in vitro, but also in vivo, calcium antagonists and beta-blockers are anti-atherosclerotic and pro-atherogenic drugs, respectively.

The effect of nifedipine on serum properties during a course has been assessed [49]. A patient received 20-mg doses of nifedipine three times a day at an 8-hour interval for 7 days. Twenty-eight days after regular nifedipine therapy, the atherogenicity of the patient's serum was considerably lower than at the beginning of the therapy. Directly after new dose of nifedipine, the intracellular cholesterol retention was not revealed. In contrast, after a course treatment with the beta-blocker propranolol, the patient's serum acquired stable atherogenic properties. At the beginning of the course, the serum of this patient did not induce intracellular cholesterol retention; however, 28 days of regular propranolol therapy led to the emergence of atherogenicity, revealed even before the drug administration.

\section{Natural Products}

Ex vivo cellular model can be used to test natural products. We have investigated prevention of intracellular cholesterol retention caused by certain mushroom species and sea products. Extracts from 20 Korean mushroom species exhibit intracellular cholesterol retention revealed by cell culture test [55]. Among sea products, mollusk and krill meat were investigated. Two hours after a single dietary load with canned meat of a mollusk belonging to the genus Buccinum, the patient's blood serum acquired marked anti-atherosclerotic properties [56]. Incubation of this serum with cultured atherosclerotic cells led to a fall in intracellular cholesterol retention. Patients of another group received a single dietary dose of Antarctic krill meat. Two hours later, the retention of cellular cholesterol induced by blood sera decreased, and four hours later, it was practically absent [56].

To develop a dietary therapy based on the krill meat, the effective dose and proper regimen have been established. The antiatherosclerotic activity of krill meat was evaluated by the ability to reduce intracellular cholesterol retention. The dose-effect dependence was revealed by comparing the efficacy of the two doses, and we found that krill meat possesses anti-atherosclerotic effects at a dose of 10-20 g, half-maximum effect was reached at a dose of $30 \mathrm{~g}$, and the maximum effect was achieved at a dose of $50 \mathrm{~g}$. We believe that this approach will be useful in the development and optimization of anti-atherosclerotic dietary therapies.

We have tested numerous extracts of natural products to reveal their effects on their capacity to prevent intracellular cholesterol retention caused by atherogenic blood sera from atherosclerotic patients. Naturally, the tested agents included anti-atherosclerotic, pro-atherogenic, and neutral products. Among the anti-atherosclerotic natural products, the most effective was garlic.

We investigated the in vitro effect of garlic extract on intracellular cholesterol retention. Garlic prevented the serum-induced accumulation of free cholesterol and reduced the accumulation of cholesteryl esters [57]. The effect of garlic on cholesteryl esters may be explained by the action on enzymes responsible for cholesteryl ester metabolism. We have shown that garlic inhibits acyl-CoA: cholesterol acyltransferase, which participates in cholesteryl ester formation, and stimulates cholesteryl ester hydrolase, which degrades cholesteryl esters [57].

Further investigations ex vivo confirmed the in vitro effects of garlic [58]. In ex vivo experiments we applied dry garlic powder. Using ex vivo model we optimized the effective dose of oral garlic powder administration. The anti-atherosclerotic activity of garlic powder was evaluated by the ability to reduce intracellular cholesterol retention. The dose-effect dependence was revealed by comparing the efficacy of the two doses, and we found that garlic powder possesses antiatherosclerotic effects at a dose of 50-300 $\mathrm{mg}$. The minimum dose causing maximum effect was $150 \mathrm{mg}$.

Using the optimal dose of $150 \mathrm{mg}$ garlic powder we have showed that long-term treatment for months and years leads to a significant reduction of intracellular cholesterol retention or its extinction $[58,59]$. These data stimulated us to develop a drug based on garlic powder and carried out a clinical study of the effects of this drug on atherosclerosis regression.

\section{Translation into Clinics}

We have developed the time-released garlic powder tablets referred to as Allicor that have been registered and are now being manufactured by INAT-Farma, Ltd. (Russia). The AMAR study (Atherosclerosis Monitoring and Atherogenicity Reduction) was carried out to estimate the effect of two-year treatment with Allicor on the progression of carotid atherosclerosis in asymptomatic men in a double-blinded, placebocontrolled randomized clinical trial (ClinicalTrials.gov Identifier, NCT01734707). The primary outcome was the rate of atherosclerosis 
progression, measured by high-resolution B-mode ultrasonography as the increase in carotid intima-media thickness (CIMT) of the far wall of common carotid arteries [59].

At the baseline, blood serum taken from patients induced 1.56fold increase in intracellular cholesterol retentio in cell culture test. In the placebo group, the mean value of serum induced intracellular cholesterol retention did not change significantly during two years. On the opposite, in Allicor-treated patients the mean level of intracellular cholesterol retention was significantly lowered already after first 3 months of treatment, and this effect was maintained during the study. We found statistically significant difference in the dynamic of changes in intracellular cholesterol retention between Allicor-treated and placebo groups. Allicor significantly reduced CIMT compared to baseline and the placebo group, while spontaneous atherosclerosis progression prevailed in the placebo group.

Our data are generally consistent with the results of a doubleblinded, placebo-controlled randomized study by Koscielny et al. [60] That study has been demonstrated that 4-year treatment with the garlicbased drug Kwai inhibited the increase in volume of atherosclerotic plaques in carotid and femoral arteries by $5-18 \%$.

Atherosclerosis regression effect of Allicor revealed in the AMAR study is comparable with the results of most successful trials with other compounds [61-68]. Those studies employed potent lipid-lowering agents or calcium antagonists, whose beneficial effects of treatment were attributed to reduction in LDL cholesterol, the major risk factor for atherosclerosis development, or arterial wall stress.

Effects of Allicor promoted new clinical trials of two other drugs based on natural products, Inflaminat, which possesses anti-cytokine activity, and the phytoestrogen-rich drug Karinat, which is designed for postmenopausal women.

Inflammatory cytokines play significant role at every stage of atherogenesis [69-71]. So, anti-cytokine drugs may be effective for the prevention of atherosclerosis. We have developed drug Inflaminat, which is based on calendula, elder and violet. Our laboratory investigations demonstrated that Inflaminat suppresses secretion of pro-inflammatory cytokines and reduces intracellular cholesterol retention. We have carried out a pilot study (Clinical Trials.gov Identifier, NCT01743404) with Inflaminat using a protocol similar to that of the AMAR study. New study demonstrated atherosclerosis regression effects of Inflaminat and a statistically significant difference from the baseline as well as from placebo group in asymptomatic men [59].

The effective approaches to atherosclerosis prevention in postmenopausal women do not exist. Hormone replacement therapy is not acceptable due to the negative results of clinical studies, including WHI, PEPI, and HERS [72-77]. Phytoestrogens may be an alternative to hormone replacement therapy, but practically nothing is known about their effects on atherosclerosis.

We selected phytoestrogen-rich botanicals on the basis of their ability to prevent intracellular cholesterol retention in ex vivo test system. The following combination was chosen: garlic powder, extract of grape seeds, green tea leaves, and hop cones, all of them produced significant anti-atherogenic effects. This combination was used for development of novel isoflavonoid-rich dietary supplement Karinat. Karinat prevents intracellular cholesterol retention and is characterized by good phytoestrogen profile, providing additional amounts of biologically active polyphenols, including resveratrol, genisteine, and daidzeine. Moreover Karinat contains additional amounts of $\beta$-carotene, $\alpha$-tocopherol and ascorbic acid to provide the necessary daily intake of antioxidants.

We have carried out a randomized, double-blinded, placebocontrolled pilot clinical trial to reveal possible atherosclerosis-related effects of Karinat in healthy postmenopausal women http://clinicaltrials. gov/ Identifiers, NCT01741974 and NCT01742000). The annual rate of changes in CIMT was monitored. In the Karinat group the average CIMT was not changed (statistically insignificant increase of $6 \mu \mathrm{m}$ per year, less than 1\%). The progression of existing plaques was slower by $32 \%$ per year. Thus, the use of Karinat in postmenopausal women almost completely suppresses the formation of new atherosclerotic lesions, and it slows the progression of existing lesions [59].

\section{Conclusion}

Our basic studies have demonstrated that intracellular cholesterol retention is the key initiating process in atherogenesis. On the basis of our data we have developed cellular models and an approach to prevent intracellular cholesterol retention. We have demonstrated that prevention of intracellular cholesterol retention leads to the prevention of atherosclerosis progression and/or its regression in patients. We can conclude that our basic findings were successfully translated into clinics.

Unfortunately, natural products with anti-atherosclerotic therapeutic potential are not prescribed by medical practitioners as anti-atherosclerotic agents. However, our data allows us to consider botanicals as anti-atherosclerotic prescriptions [78].

\section{Conflict of Interest}

The author confirms that this article presents no conflicts of interest.

\section{Acknowledgement}

This work was supported by the Russian Ministry of Education and Science.

\section{References}

1. Martin SS, Blumenthal RS, Miller M (2012) LDL cholesterol: the lower the better. Med Clin North Am 96: 13-26.

2. Sala F, Catapano AL, Norata GD (2012) High density lipoproteins and atherosclerosis: emerging aspects. J Geriatr Cardiol 9: 401-407.

3. Fisher EA, Feig JE, Hewing B, Hazen SL, Smith JD (2012) High-density lipoprotein function, dysfunction, and reverse cholesterol transport. Arterioscler Thromb Vasc Biol 32: 2813-2820.

4. Williams KJ, Tabas I (1995) The response-to-retention hypothesis of early atherogenesis. Arterioscler Thromb Vasc Biol 15: 551-561.

5. Williams KJ, Tabas I (1998) The response-to-retention hypothesis of atherogenesis reinforced. Curr Opin Lipidol 9: 471-474.

6. Tabas I, Williams KJ, Borén J (2007) Subendothelial lipoprotein retention as the initiating process in atherosclerosis: update and therapeutic implications. Circulation 116: 1832-1844.

7. Insull W Jr (2009) The pathology of atherosclerosis: plaque development and plaque responses to medical treatment. Am J Med 122: S3-3S14.

8. Moore KJ, Freeman MW (2008) Targeting Innate Immunity for CV Benefit. Drug Discov Today Ther Strateg 5: 15-23.

9. Orekhov AN, Tertov VV, Kudryashov SA, Smirnov VN (1990) Triggerlike stimulation of cholesterol accumulation and DNA and extracellular matrix synthesis induced by atherogenic serum or low density lipoprotein in cultured cells. Circ Res 66: 311-320.

10. Orekhov AN, Tertov VV, Pokrovsky SN, Adamova IYu, Martsenyuk ON, et al. (1988) Blood serum atherogenicity associated with coronary atherosclerosis. Evidence for nonlipid factor providing atherogenicity of low-density lipoproteins and an approach to its elimination. Circ Res 62: 421-429.

11. Kruth HS (2011) Receptor-independent fluid-phase pinocytosis mechanisms 
for induction of foam cell formation with native low-density lipoprotein particles. Curr Opin Lipidol 22: 386-393.

12. Yuan Y, Li P, Ye J (2012) Lipid homeostasis and the formation of macrophagederived foam cells in atherosclerosis. Protein Cell 3: 173-181.

13. Orekhov AN, Tertov VV, Mukhin DN, Mikhailenko IA (1989) Modification of low density lipoprotein by desialylation causes lipid accumulation in cultured cells: discovery of desialylated lipoprotein with altered cellular metabolism in the blood of atherosclerotic patients. Biochem Biophys Res Commun 162: 206211.

14. Orekhov AN, Tertov VV, Mukhin DN (1991) Desialylated low density lipoprotein--naturally occurring modified lipoprotein with atherogenic potency. Atherosclerosis 86: 153-161.

15. Tertov VV, Sobenin IA, Gabbasov ZA, Popov EG, Orekhov AN (1989) Lipoprotein aggregation as an essential condition of intracellular lipid accumulation caused by modified low density lipoproteins. Biochem Biophys Res Commun 163: 489494.

16. Tertov VV, Sobenin IA, Tonevitsky AG, Orekhov AN, Smirnov VN (1990) Isolation of atherogenic modified (desialylated) low density lipoprotein from blood of atherosclerotic patients: separation from native lipoprotein by affinity chromatography. Biochem Biophys Res Commun 167: 1122-1127.

17. Tertov VV, Sobenin IA, Orekhov AN, Jaakkola O, Solakivi T, et al. (1996) Characteristics of low density lipoprotein isolated from circulating immune complexes. Atherosclerosis 122: 191-199.

18. Tertov VV, Kaplun VV, Sobenin IA, Boytsova EY, Bovin NV, et al. (2001) Human plasma trans-sialidase causes atherogenic modification of low density lipoprotein. Atherosclerosis 159: 103-115.

19. Avogaro P, Bon GB, Cazzolato G (1988) Presence of a modified low density lipoprotein in humans. Arteriosclerosis 8: 79-87.

20. Krauss RM, Burke DJ (1982) Identification of multiple subclasses of plasma low density lipoproteins in normal humans. J Lipid Res 23: 97-104.

21. Tertov VV, Bittolo-Bon G, Sobenin IA, Cazzolato G, Orekhov AN, et al. (1995) Naturally occurring modified low density lipoproteins are similar if not identical: more electronegative and desialylated lipoprotein subfractions. Exp Mol Pathol 62: $166-172$

22. Tertov VV, Sobenin IA, Orekhov AN (1996) Similarity between naturally occurring modified desialylated, electronegative and aortic low density lipoprotein. Free Radic Res 25: 313-319.

23. La Belle M, Krauss RM (1990) Differences in carbohydrate content of low density lipoproteins associated with low density lipoprotein subclass patterns. J Lipid Res 31: 1577-1588.

24. Orekhov AN, Tertov VV, Kabakov AE, Adamova IYu, Pokrovsky SN, et al. (1991) Autoantibodies against modified low density lipoprotein. Nonlipid factor of blood plasma that stimulates foam cell formation. Arterioscler Thromb 11: 316-326.

25. Orekhov AN, Tertov VV (1991) Atherogenicity of autoantibodies against low density lipoprotein. Agents Actions 32: 128-129.

26. Lopes-Virella MF, Virella G (2010) Clinical significance of the humoral immune response to modified LDL. Clin Immunol 134: 55-65.

27. Tertov VV, Orekhov AN, Sayadyan KhS, Serebrennikov SG, Kacharava AG et al. (1990) Correlation between cholesterol content in circulating immune complexes and atherogenic properties of CHD patients' serum manifested in cell culture. Atherosclerosis 81: 183-189.

28. Kacharava AG, Tertov VV, Orekhov AN (1993) Autoantibodies against lowdensity lipoprotein and atherogenic potential of blood. Ann Med 25: 551-555.

29. Tertov VV, Orekhov AN, Kacharava AG, Sobenin IA, Perova NV, et al. (1990) Low density lipoprotein-containing circulating immune complexes and coronary atherosclerosis. Exp Mol Pathol 52: 300-308.

30. Orekhov AN, Kalenich OS, Tertov VV, Novikov ID (1991) Lipoprotein immune complexes as markers of atherosclerosis. Int J Tissue React 13: 233-236.

31. Orekhov AN, Kalenich OS, Tertov VV, Perova NV, Novikov lyD, et al. (1995) Diagnostic value of immune cholesterol as a marker for atherosclerosis. J Cardiovasc Risk 2: 459-466.

32. Sobenin IA, Karagodin VP, Melnichenko AC, Bobryshev YV, Orekhov AN (2013) Diagnostic and prognostic value of low density lipoprotein-containing circulating immune complexes in atherosclerosis. J Clin Immunol 33: 489-495.
33. Sobenin IA, Orekhova VA, Melnichenko AA, Bobryshev YV, Orekhov AN (2013) Low density lipoprotein-containing circulating immune complexes have better prognostic value in carotid intima-media thickness progression than other lipid parameters. Int J Cardiol 166: 747-748.

34. Orekhov AN, Tertov VV, Mukhin DN, Koteliansky VE, Glukhova MA, et al. (1989) Insolubilization of low density lipoprotein induces cholesterol accumulation in cultured subendothelial cells of human aorta. Atherosclerosis 79: 59-70.

35. Glukhova MA, Kabakov AE, Frid MG, Ornatsky OI, Belkin AM, et al. (1988) Modulation of human aorta smooth muscle cell phenotype: a study of musclespecific variants of vinculin, caldesmon, and actin expression. Proc Natl Acad Sci U S A 85: 9542-9546.

36. Orekhov AN, Tertov VV, Mukhin DN, Koteliansky VE, Glukhova MA, et al. (1987) Association of low-density lipoprotein with particulate connective tissue matrix components enhances cholesterol accumulation in cultured subendothelial cells of human aorta. Biochim Biophys Acta 928: 251-258.

37. Melnichenko AA, Aksenov DV, Myasoedova VA, Panasenko OM, Yaroslavov AA, et al. (2012) Pluronic block copolymers inhibit low density lipoprotein selfassociation. Lipids 47: 995-1000.

38. Tertov VV, Orekhov AN, Sobenin IA, Gabbasov ZA, Popov EG, et al. (1992) Three types of naturally occurring modified lipoproteins induce intracellular lipid accumulation due to lipoprotein aggregation. Circ Res 71: 218-228.

39. Rekhter MD, Andreeva ER, Mironov AA, Orekhov AN (1991) Three-dimensiona cytoarchitecture of normal and atherosclerotic intima of human aorta. Am J Pathol 138: 569-580.

40. Orekhov AN, Andreeva ER, Krushinsky AV, Smirnov VN (1984) Primary cultures of enzyme-isolated cells from normal and atherosclerotic human aorta. Med Biol 62: 255-259.

41. Orekhov AN, Tertov VV, Novikov ID, Krushinsky AV, Andreeva ER, et al (1985) Lipids in cells of atherosclerotic and uninvolved human aorta. I. Lipid composition of aortic tissue and enzyme-isolated and cultured cells. Exp Mol Pathol 42: 117-137.

42. Orekhov AN, Krushinsky AV, Andreeva ER, Repin VS, Smirnov VN (1986) Adult human aortic cells in primary culture: heterogeneity in shape. Heart Vessels 2: 193-201.

43. Yamada S, Guo X, Yoshizawa M, Li Z, Matsuyama A, et al (2011) Primary desmoplastic cutaneous leiomyosarcoma associated with high MIB-1 labeling index: a teaching case giving rise to diagnostic difficulties on a small biopsy specimen. Pathol Res Pract 207: 728-732.

44. Orekhov AN, Kosykh VA, Repin VS, Smirnov VN (1983) Cell proliferation in normal and atherosclerotic human aorta. II. Autoradiographic observation on deoxyribonucleic acid synthesis in primary cell culture. Lab Invest 48: 749-754.

45. Orekhov AN, Tertov VV, Kudryashov SA, Khashimov KhA, Smirnov VN (1986) Primary culture of human aortic intima cells as a model for testing anti-atherosclerotic drugs. Effects of cyclic AMP, prostaglandins, calcium antagonists, antioxidants, and lipid-lowering agents. Atherosclerosis 60: 101110.

46. Chazov El, Tertov VV, Orekhov AN, Lyakishev AA, Perova NV, et al. (1986) Atherogenicity of blood serum from patients with coronary heart disease. Lancet 2: 595-598.

47. Tertov VV, Orekhov AN, Ryong LH, Smirnov VN (1988) Intracellular cholestero accumulation is accompanied by enhanced proliferative activity of human aortic intimal cells. Tissue Cell 20: 849-854.

48. Tertov VV, Orekhov AN, Martsenyuk ON, Perova NV, Smirnov VN (1989) Lowdensity lipoproteins isolated from the blood of patients with coronary heart disease induce the accumulation of lipids in human aortic cells. Exp Mol Pathol 50: $337-347$

49. Orekhov AN (1990) In vitro models of anti-atherosclerotic effects of cardiovascular drugs. Am J Cardiol 66: 23I-28I.

50. Palatini $P$ (2009) Elevated heart rate in cardiovascular diseases: a target for treatment? Prog Cardiovasc Dis 52: 46-60.

51. Schulman IH, Zachariah M, Raij L (2005) Calcium channel blockers, endothelial dysfunction, and combination therapy. Aging Clin Exp Res 17: 40-45.

52. Orekhov AN, Baldenkov GN, Tertov VV, Ryong LH, Kozlov SG, et al. (1988) Cardiovascular drugs and atherosclerosis: effects of calcium antagonists, betablockers, and nitrates on atherosclerotic characteristics of human aortic cells. Cardiovasc Pharmacol 12 Suppl 6: S66-68. 
53. Loaldi A, Polese A, Montorsi P, De Cesare N, Fabbiocchi F, et al. (1989) Comparison of nifedipine, propranolol and isosorbide dinitrate on angiographic progression and regression of coronary arterial narrowings in angina pectoris. Am J Cardiol 64: 433-439.

54. Orekhov AN, Baldenkov GN, Tertov VV, Ruda MYa, Khashimov KA, et al. (1990) Antiatherosclerotic effects of calcium antagonists. Study in human aortic cell culture. Herz 15: 139-145.

55. Li HR, Tertov VV, Vasil'ev AV, Tutel'yan VA, Orekhov AN (1989) Anti-atherogenic and anti-atherosclerotic effects of mushroom extracts revealed in human aortic intima cell culture. Drug Devel Res 17: 109-117.

56. Orekhov AN (2013) Direct anti-atherosclerotic therapy; development of natural anti-atherosclerotic drugs preventing cellular cholesterol retention. Curr Pharm Des 19: 5909-5928.

57. Orekhov AN, Tertov VV (1997) In vitro effect of garlic powder extract on lipid content in normal and atherosclerotic human aortic cells. Lipids 32: 1055-1060.

58. Orekhov AN, Grünwald J (1997) Effects of garlic on atherosclerosis. Nutrition 13: $656-663$

59. Orekhov AN, Sobenin IA, Korneev NV, Kirichenko TV, Myasoedova VA, et al. (2013) Anti-atherosclerotic therapy based on botanicals. Recent Pat Cardiovasc Drug Discov 8: 56-66

60. Koscielny J, Klüssendorf D, Latza R, Schmitt R, Radtke H, et al. (1999) The antiatherosclerotic effect of Allium sativum. Atherosclerosis 144: 237-249.

61. Crouse JR 3rd, Byington RP, Bond MG, Espeland MA, Craven TE, et al. (1995) Pravastatin, Lipids, and Atherosclerosis in the Carotid Arteries (PLAC-II) Am J Cardiol 75: 455-459.

62. Salonen R, Nyyssönen K, Porkkala E, Rummukainen J, Belder R, et al. (1995) Kuopio Atherosclerosis Prevention Study (KAPS). A population-based primary preventive trial of the effect of LDL lowering on atherosclerotic progression in carotid and femoral arteries. Circulation 92: 1758-1764.

63. Smilde TJ, van Wissen S, Wollersheim H, Trip MD, Kastelein JJ, et al. (2001) Effect of aggressive versus conventional lipid lowering on atherosclerosis progression in familial hypercholesterolaemia (ASAP): a prospective, randomised, double-blind trial. Lancet 357: 577-581.

64. Pitt B, Byington RP, Furberg CD, Hunninghake DB, Mancini GB, et al. (2000) Effect of amlodipine on the progression of atherosclerosis and the occurrence of clinical events. PREVENT Investigators. Circulation 102: 1503-1510.

65. Blankenhorn DH, Selzer RH, Crawford DW, Barth JD, Liu CR, et al. (1993) Beneficial effects of colestipol-niacin therapy on the common carotid artery. Two- and four-year reduction of intima-media thickness measured by ultrasound. Circulation 88: 20-28.

66. Hodis HN (1995) Reversibility of atherosclerosis--evolving perspectives from two arterial imaging clinical trials: the cholesterol lowering atherosclerosis regression study and the monitored atherosclerosis regression study. Cardiovasc Pharmacol 25 Suppl 4: S25-S31.

67. Blankenhorn DH, Azen SP, Kramsch DM, Mack WJ, Cashin-Hemphill L, et al (1993) Coronary angiographic changes with lovastatin therapy. The Monitored Atherosclerosis Regression Study (MARS). Ann Intern Med 119: 969-976.

68. Zanchetti A, Rosei EA, Dal Palù C, Leonetti G, Magnani B, et al. (1998) The Verapamil in Hypertension and Atherosclerosis Study (VHAS): results of longterm randomized treatment with either verapamil or chlorthalidone on carotid intima-media thickness. J Hypertens 16: 1667-1676.

69. Libby P (2006) Inflammation and cardiovascular disease mechanisms. Am J Clin Nutr 83: 456S-460S

70. Aidinian G, Weiswasser JM, Arora S, Abularrage CJ, Singh N, et al. (2006) Carotid plaque morphologic characteristics. Perspect Vasc Surg Endovasc Ther 18: 63-70.

71. Daugherty A, Webb NR, Rateri DL, King VL (2005) Thematic review series: The immune system and atherogenesis. Cytokine regulation of macrophage functions in atherogenesis. J Lipid Res 46: 1812-1822.

72. Burger HG, MacLennan AH, Huang KE, Castelo-Branco C (2012) Evidencebased assessment of the impact of the WHI on women's health. Climacteric 15: 281-287.

73. de Villiers TJ, Stevenson JC (2012) The WHI: the effect of hormone replacement therapy on fracture prevention. Climacteric 15: 263-266.

74. Ellis MJ, Suman VJ, Hoog J, Lin L, Snider J, et al. (2011) Randomized phase II neoadjuvant comparison between letrozole, anastrozole, and exemestane for postmenopausal women with estrogen receptor-rich stage 2 to 3 breast cancer: clinical and biomarker outcomes and predictive value of the baseline PAM50-based intrinsic subtype--ACOSOG Z1031. J Clin Oncol 29: 2342-2349.

75. Smith NL, Wiley JR, Legault C, Rice KM, Heckbert SR, et al. (2008) Effect of progestogen and progestogen type on hemostasis measures in postmenopausal women: the Postmenopausal Estrogen/Progestin Intervention (PEPI) Study. Menopause 15: 1145-1150.

76. Masood DE, Roach EC, Beauregard KG, Khalil RA (2010) Impact of sex hormone metabolism on the vascular effects of menopausal hormone therapy in cardiovascular disease. Curr Drug Metab 11: 693-714.

77. Pellegrini CN, Vittinghoff E, Lin F, Hulley SB, Marcus GM (2009) Statin use is associated with lower risk of atrial fibrillation in women with coronary disease: the HERS trial. Heart 95: 704-708.

78. Slevin M, Ahmed N, Wang Q, McDowell G, Badimon L (2012) Unique vascular protective properties of natural products: supplements or future main-line drugs with significant anti-atherosclerotic potential? Vasc Cell 4: 9. 